\title{
DE CAMELÔS A LOJISTAS: a transição do mercado de rua para um shopping em Porto Alegre
}

\author{
Moisés Kopper*
}

\begin{abstract}
Este artigo parte das tensões envolvidas no processo de remoção do mercado de rua do centro de Porto Alegre/RS e sua realocação para um shopping popular, construído através de uma Parceira Público-Privada (PPP). Privilegia-se a abordagem etnográfica, baseada numa inserção de campo de mais de três anos, que permitiu captar o processo em perspectiva diacrônica. A transição das ruas para o camelódromo foi acompanhada de perto pela empresa construtora, doravante responsável pela sua administração, que exigiu uma mudança na sensibilidade comercial, a partir de uma política de pedagogização, visando forjar novos perfis de comerciantes, algo indispensável ao sucesso econômico do empreendimento. Como consequência, novas modalidades de conflitos emergem diariamente dessa estratégia, pois, nem todos os camelôs se reconverteram no protótipo de lojista idealizado pela PPP. As tensões em torno desse processo permitem reconstituir os nexos entre economia e política, micro e macro, agentes e instituições que configuram o social. Palavras-chave: Mercado Informal. Camelôs. Estado. Etnografia. Parceria Público-Privada.
\end{abstract}

\section{INTRODUÇÃO}

Desde os tempos mais remotos, os mercadores de rua existem em toda parte e são um componente essencial da paisagem e arquitetura das grandes cidades. Suas origens são tão diversas - e complexas de serem traçadas - quanto os espaços que ocupam nas metrópoles, a diversidade de trajetórias que encerram e a maleabilidade com que circulam pela malha urbana. Se a heterogeneidade desse universo é demasiadamente ampla, devo acrescentar que os grupos que constituem o ponto de partida deste artigo são formados por camelôs, um tipo peculiar de comerciantes de rua que se identificam pelo mesmo termo, que carregam estratégias particulares de ocupação do espaço urbano, baseadas, por sua vez, em códigos éticos e estéticos específicos.

Não há consenso sobre o termo mais adequado para designar os comerciantes de rua. A noção de ambulante - ou camelô -, pela qual o

* Universidade Federal do Rio Grande do Sul. Avenida Bento Gonçalves, 9500, Prédio 43311, Bloco AI, Sala $104^{\mathrm{a}}$. Cep: 91509-90. Porto Alegre - Rio Grande do Sul-Brasil. moiseskopper@gmail.com.
Estado habitualmente se pronuncia para referi-los, carrega uma conotação de expropriação, de alguém que não é senhor de sua terra e, por conseguinte, não é tido como cidadão. A noção de informal é, paradoxalmente, por demais ampla e restrita. É ampla porque, se pensada sob a ótica da formalidade - entenda-se legalidade -, acaba se dispersando num leque variado de atividades que, no Brasil, ocupa quase $50 \%$ da mão de obra ativa. Ao mesmo tempo, o conceito de informalidade é restritivo, pois focaliza apenas os aspectos jurídicos e tributáveis. Naturalizando os parâmetros legais, a noção de "informal" transforma as práticas do comércio de rua em meros desvios de conduta, empobrecendo, sobremaneira, os seus significados contextuais (Aguiar, 2007; Cunha, 2006; Machado da Silva, 2002; Mafra, 2005; Noronha, 2003; Pinheiro-Machado, 2004; 2009; Rabossi, 2004; Ribeiro, 2006; 2010).

Não trato aqui do mercado de rua ou de camelôs em geral, mas de um processo de reassentamento que envolveu o deslocamento de aproximadamente 800 bancas instaladas nas ruas do centro histórico de Porto Alegre para um espaço fechado. Anunciado em 2005, com 
a mudança da gestão municipal, o "Centro Popular de Compras" (CPC) - ou, simplesmente, "Camelódromo", como ficaria conhecido entre os trabalhadores, embora sua nomenclatura sofresse outras alterações com o andamento da transição - seria tomado como a marca da nova administração, tendo sido aberto à população em fevereiro de 2009 e, portanto, tendo contribuído para a reeleição do mesmo bloco de partidos ao poder. Ao longo do processo de implementação, ficaria claro que a mesma maleabilidade, que garantira, até então, a sobrevivência de toda uma categoria de trabalhadores nas ruas do centro, teria de ser empregada, doravante, para reacomodar e reordenar, compulsoriamente, seus projetos de vida. Desta vez, contudo, não mais nas vias e calçadas, mas nas fronteiras das novas bancas, de $4 \mathrm{~m}^{2}$, situados sobre uma superfície de $20.000 \mathrm{~m}^{2}$ dividida em dois grandes blocos - A e B -, que se mostrariam, respectivamente, os mais e menos prestigiosos em termos de fluxos de clientes e movimentações econômicas.

Localizado na Praça Ruy Barbosa, sobre dois terminais de ônibus, em pleno "coração" da cidade - a algumas quadras da Prefeitura Municipal, do Mercado Público, e em duas das vias de comércio popular mais frequentadas por compradores de todo o estado, o camelóD dromo passaria por uma série de modificações $\stackrel{\sim}{*}$ em seu projeto e estrutura, de acordo com o Фั andamento das negociações entre as três modelidades de agentes envolvidos em sua conš cretização: os camelôs que ocupavam as ruas

\& Parceria Público-Privada (PPP) com a empresa

$\stackrel{\sim}{\sim}$ Verdicon S.A., de acordo com o qual o poder

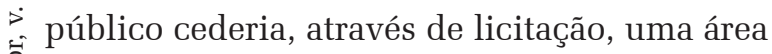
nobre no coração do centro para a construção de um espaço capaz de abrigar, contiguamente, 800 camelôs devidamente cadastrados junto à Secretaria Municipal de Produção, Indústria e Comércio (SMIC). A empresa assumiria o ônus da construção do edifício e, como contraparti- da, lhe seria concedido o direito de exploração do empreendimento através da cobrança de aluguéis semanais dos novos inquilinos.

A realocação dos camelôs de Porto Alegre foi um projeto ousado e inovador por parte dos gestores municipais. Embora não tenha sido o primeiro do gênero no Brasil, envolveu um conjunto extenso de variáveis que precisaram ser equacionadas com habilidade, sendo a principal delas, sem dúvida, o consentimento dos próprios camelôs. O uso da repressão pura e simples se mostrou, ao longo dos anos, uma estratégia economicamente inócua - pois os camelôs mudam de lugar ou retornam depois de certo tempo -, e politicamente desgastante - uma vez que os camelôs se reivindicam como trabalhadores honestos e encontram nisso solidariedade junto ao público mais amplo. Assim, com o contrato de PPP, celebrado em 2006, o poder público correspondia, simultaneamente, às expectativas dos setores da economia formal, que exigiam a reurbanização e higienização do centro de Porto Alegre, como condição para seu sucesso comercial, quanto aos anseios da opinião pública, que via com certa resistência o investimento de recursos públicos vultosos para tratar de um setor malquisto da população e que, ademais, nem bem eram residentes da capital ${ }^{1}$.

Argumento, conforme Kopper (2012), que a estes processos podemos nos referir, respectivamente, através das ideias de gentrificação (Leite, 2001; 2002) e de governamentalidade (Foucault, 1979). Muitos autores já discutiram os diferentes processos pelos quais os centros urbanos das grandes cidades vão, paulatinamente, passando por ciclos que alternam desocupação e degradação com reurbanização e patrimonialização. No caso específico que me ocupa, a gentrificação de prédios e ruas históricas tinha o objetivo, mais que de devolvê-los aos assim considerados "cidadãos de direito",

${ }^{1}$ Uma parte expressiva desses comerciantes não era residente na própria capital, mas nos municípios do entorno - consequência direta do adensamento do comércio informal nos anos 1980 -, o que tornava arriscado tentar justificar, aos porto-alegrenses, a destinação de seus tributos para o atendimento dessas demandas. 
ou de propiciar-lhes um novo "ângulo" de contemplação desses patrimônios, promover uma nova instilação econômica, tratando de reconduzir a classe média - em permanente expansão - para esses espaços outrora ocupados.

O camelódromo inseria-se, assim, como parte desse processo, já que, simultaneamente, removia sujeitos indesejáveis, onerosos e perigosos à economia formal, oxigenando-a, ao mesmo tempo em que os submetia, por meio de uma série de políticas de formalização subsequentes à ocupação do prédio, à conversão em comerciantes populares ou ainda microempresários. Mais que um jogo de palavras, tais ações de marketing visaram à fabricação de uma nova subjetividade comercial, por sua vez adequada à proposição do camelódromo como "shopping popular", vale dizer, como receptáculo de novos fluxos de clientela que tinha interesse nessa modalidade de mercado em reconfiguração.

\section{AS ESTRATÉGIAS POLÍTICAS DE SOBREVIVÊNCIA ECONÔMICA}

As diversas medidas paliativas, tentadas ao longo dos anos 1990 para a readequação dos camelôs, produziram uma série de dissidências internas, que terminaram por estabelecer duas grandes facções quando o camelódromo entrou na pauta de discussões, em 2005: de um lado, havia a Associação Feira da Rua da Praia (ASFERAP), que surgiu no final dos anos 1990, devido a irregularidades na ocupação da Rua da Praia, e que, desde sempre, precisou negociar a sua permanência nas ruas com o poder público. Em função de não poderem permanecer durante todo o dia nas ruas, demandavam o título de feirantes. A expansão desse grupo foi relativamente rápida e, apesar de pouco capitalizados, passaram a reunir grande parte dos ambulantes que, diariamente, vinham da região metropolitana de Porto Alegre.

Isso despertou a atenção dos grupos de camelôs estabelecidos, há mais tempo, no en- torno da Praça XV. Na verdade, era ali que se concentrava a maior parte dos ambulantes do centro, ao menos aqueles que, ao longo dos anos 1990, foram oficialmente cadastrados para exercerem suas atividades em praça pública. Entre ambas as facções não havia diferenças sociais e econômicas significativas; na verdade, o termo facção, de uso específico na antropologia da política, não é gratuito, visto que era no campo da política que os conflitos e as dissemelhanças emergiam. E, para entender a forma como elas implicaram no desenho atual do camelódromo, é preciso atentar para a agência de seus mediadores - isto é, dos líderes em torno dos quais, como nas cerimônias de troca e rivalidade do Potlatch, as disputas ganhavam vida. O grupo de camelôs da Rua da Praia era coordenado, desde a sua fundação, por Juliano Fripp, uma liderança que, entre outras coisas, militava em partidos de extrema esquerda, tendo se candidatado algumas vezes a cargos políticos. O grupo de camelôs da Praça XV era coordenado por Alfonso Limberger, um sujeito sem grandes habilidades para a política profissional, mas que não hesitava em acioná-la quando se tratava de garantir benefícios ao seu grupo.

A adesão ao projeto de camelódromo, por parte desses camelôs, não foi unívoca, nem homogênea. Por diversas vezes, esses dois grupos alternaram-se na mesa de negociações com o poder público. Juliano, de início, era a favor da remoção; Alfonso era contra. Com a divisão dos boxes, meses antes da abertura do empreendimento, essas posições se inverteram. O grupo de Juliano ficou com os pontos menos valorizados, nos fundos do bloco $\mathrm{B}$, ao mesmo tempo em que Alfonso resolvia aderir às regras estabelecidas, criando parcerias no governo e na empresa. Juliano optou pelo enfrentamento, para que o empreendimento produzisse sustentabilidade social e não extinguisse, como se previa, os "camelôs" como categoria de trabalhadores. Alfonso passou a atuar pelos bastidores do camelódromo, na prospecção de novos membros para a associação e na negociação direta com a empresa. Juliano organi- 
zou uma mobilização política por dentro do Estado, que teve certa repercussão durante o primeiro ano de funcionamento, acionando o Ministério Público, a Câmara de Vereadores, a Prefeitura Municipal e a mídia.

À medida que o empreendimento tomava forma, Alfonso passou a enxergá-lo como uma grande oportunidade de propulsionar as vendas, suas e de seu grupo. Para tanto, bastava adequar a sabedoria comercial, adquirida durante anos de trabalho nas ruas, e equacioná-la para que seus colegas pudessem apropriá-la como medida do bom comerciante, do camelô ajustado aos novos tempos e recursos. A esse movimento, Alfonso chamou de profissionalização da figura o camelô. Mais que uma reinvenção, tratava-se de inventariar as técnicas de comércio já existentes na rua, entre os camelôs da Praça XV, agregando e ajustando-as à nova ordem entre sujeito, lugar e coisa, fruto dos novos fluxos de pessoas, de capital e de clientes do camelódromo. Essa nova gramática das relações sociais estava fundamentada na perda da autonomia do sujeito camelô diante de seu produto e de seu cliente: um novo perfil de comerciante, arrojado, atento às tendências da moda e do consumo atuais, preocupado com as oportunidades do momento e em estar à frente de seus colegas, passou a estabelecer novas hierarquias entre os sujeitos. Entre aqueles capazes de prever as novas tendências e antecipar os produtos, aumentando cada vez mais o dinheiro em circulação e a frequência de viagens ao Paraguai, Uruguai e São Paulo, e aqueles que, sem essa sensibilidade, deveriam is se contentar com lucros menores, sonhos de is expansão mais pacatos, simples intermediá$\dot{a}$ rios de mercadorias. Nas palavras de Alfonso:

O meu papel ali é fazer o meu povo ganhar dinheiro. [...] Eu trabalho muito envolvido com a profissionalização, dando instrução e acompanhando o que ta comprando, o que ta vendendo. Faltou que eu pudesse invadir as outras áreas. Invadir tecnicamente pra qualificar o pessoal. De que forma nós vamos? Agora, quando os brigão, que me ofendiam, me atiravam pedra e o diabo a quatro, chegam em mim 'oh, Alfonso, como é que eu faço pra isso [...]'. Em pri- meiro lugar, cria relação com as pessoas! Começa a conversar e ver quem que ta crescendo, pra onde vai. Eles não vão te dar a letra de cara! Aprende a ser comerciante. Aprende a comprar. Sai de dentro de casa e vai para o mundo! [...] 'Ah, mas tu só vende isso, só vende aquilo'. Mas ele vende e trocou o carro, e tu, ta criticando, por que não faz o mesmo? Já que não tem a qualidade de criar, tenha a capacidade de copiar! Nem tudo se cria, tudo se copia! (Alfonso)

Nesse processo, a agência mediadora de Alfonso estava, entre outras coisas, em instigar as relações de concorrência e de inveja, ao menos da "boa inveja", aquela que permitia ao comerciante estar atento às ações e estratégias de seus vizinhos de banca, que permitia, enfim, copiar suas táticas de comércio. $\mathrm{Ou}$ até, por que não, comprar o ponto do colega, sublocá-lo ou propor parcerias, caso ele não suporte o ritmo do jogo e desista do negócio. Ofertas cada vez mais generosas passaram a se acumular pelos corredores do camelódromo, com negociações de pontos ultrapassando $\mathrm{R} \$$ 50mil, nesse pequeno mercado imobiliário local. Assim, pequenos atacados e núcleos de comércio acabaram por se formar, sobretudo no bloco A, onde Alfonso conseguia prospectar a maior parte dos camelôs, com bancas acopladas umas às outras, auxiliares e funcionários de venda, música ambiente, máquinas de cartão de crédito, internet, telefones, mostradores, manequins, e por aí afora.

\begin{abstract}
O vendedor é pra produto encalhado, certo? Então a partir do momento em que tu qualifica ele a aprender a comprar, não é só comprar barato; comprar barato não é uma boa compra, porque ele te vende pra ele desencalhar. É comprar o que o povo ta consumindo. Saber comprar, prever o que vai ser moda daqui a três meses, ver qual é a novela, é, sim, ver a novela, mesmo, a novela vende pra caramba, todas elas [...] (Alfonso).
\end{abstract}

Alfonso também desenvolveu um acurado senso estatístico, que lhe permitia prever o que ocorreria com seus colegas e potenciais concorrentes: cerca de 25\% cairia logo de início, outros tantos desistiriam nas primeiras semanas. E, à medida que as desistências se assomavam, como resultado do fracasso eco- 
nômico individual, mas, também, do desgaste político das mobilizações empreendidas pelo seu adversário, mais e mais pessoas lhe procuravam como representante legítimo do Camelódromo. Além de intermediar as expectativas dos camelôs com a empresa e o governo, Alfonso lhes ensinava como manter e ampliar a banca. Ao mesmo tempo, ensinava os camelôs a fazerem uso da retórica do comerciante popular, o que significava passar a encarar o próprio negócio como um empreendimento pessoal, e o pagamento do aluguel como o resultado positivo dessa competência de vendas adquirida pelo empenho individual. Com o crescimento das bancas, e a aceitação e incorporação dessa pedagogia de vendas, Alfonso passou a ensinar como administrar o dinheiro e como lidar com os imprevistos financeiros e a inveja de colegas, vizinhos e parentes em alerta. O sucesso do empreendimento de cada novo comerciante popular passou, assim, também, a ser o sucesso pessoal de Alfonso, como narrador e mediador legítimo dessas trajetórias de transição e ascensão social.

Tudo tem jeito. Ali se resolve as coisas. Tu não perde, alguém recolhe a conta pra ti, faça uma parceria, a gente ensina como fazer, e tu continua ganhando o teu dinheiro. Pronto. Amanhã ou depois, estou no mercado de novo. A rotatividade faz parte do negócio, é normal em qualquer coisa. Quem que nunca foi cortada a água por falta de pagamento? Ou a luz por falta de pagamento? Isso aí [...] Não pode é fechar. (Alfonso)

\section{O COTIDIANO DA ADMINISTRAÇÃO}

Alfonso, contudo, não estava sozinho nessa empreitada que visava pedagogizar as sensibilidades comerciais dos antigos camelôs, agora considerados comerciantes populares. Para Elaine Deboni, empresária de sucesso, que passou a representar a empresa Verdicon S.A. na administração do empreendimento, não bastava apenas fazer com que os camelôs vendessem para pagar o aluguel. Tratava-se, mais fundamentalmente, de elevar o "nível" do camelódromo ao estatuto de "shopping popular", destinado ao consumo de uma "nova classe média”, que deveria voltar a ocupar o centro após uma série de políticas de revitalização que incluíam a própria remoção dos camelôs das ruas, e, com isso, também formar novos padrões de vendedores. Na prática, Elaine aproveitou uma crise de inadimplência dos aluguéis, que partiam, sobretudo, do grupo de comerciantes queixosos e menos capitalizados, liderados por Juliano. Isso lhe permitiu empreender um arrojado projeto de ressocialização social e econômica desses trabalhadores que, mais do que salvar a empresa da bancarrota a que tinha chegado pela inadimplência, tinha o objetivo de torná-los bons pagadores, para que não oferecessem resistência às campanhas de marketing que passariam a ser conduzidas pela empresa para recuperar a imagem política e socialmente desgastada que havia sido deixada pela ideia do Camelódromo como um amontoado de ambulantes e bugigangas sem valor.

Recém-especializada em Consultoria de Imagem pelo Instituto Marangoni, de Londres, Elaine trabalhou durante 24 anos com o mercado de moda de luxo, em Erechim/RS, uma cidade de cerca de cem mil habitantes, situada no norte do estado, a aproximadamente $300 \mathrm{~km}$ de Porto Alegre. Quando a empresa Verdicon S.A., gerenciada pelo seu marido, decidiu ingressar no processo de licitação para a construção do CPC - que serviria como uma espécie de aposentadoria de segunda ordem para a família Deboni -, poucos imaginaram que, como condição para reaver os investimentos financeiros realizados, seria preciso promover uma reeducação da sensibilidade comercial dos camelôs afetados pelo processo de transição. Em questão de dias, diante dos problemas deflagrados pelos protestos encabeçados por um dos grupos de camelôs queixosos e inadimplentes, a nova diretora deixaria evidente sua avidez por aplicar os conceitos aprendidos no exterior. 
Quando eu cheguei, a situação era gravíssima! [...] Eles não tinham esperança de nada. A vida pra eles já foi ruim! Eles estão no meio da rua, então pra eles se um filho conseguir um trabalho na Colombo, lá não sei aonde, tava bom. [...] E daí o que eu pensei: tu não torce uma vara velha, mas um galho novo tu torce. E eu puxei esses filhos pra cá, porque eu só trabalho os jovens, o velho não adianta. [...] Uma das coisas que eu fiz foi tirar a cara de bad boy deles. Eles não têm personagem. Então tinha um cara com camiseta de física, todo musculoso, aquele cabelo levantado, e eu com um copo de água fui baixando [risos]. Aí ele dizia, 'dona Elaine, o que a senhora ta fazendo comigo?'. Eu disse 'fecha teus olhos, eu estou esculpindo um homem. Quando tu acordar, tu vai ser outro'. Aí colocamos uma camisa, um blazer [...] Pode ver quem é o cara hoje: um baita homem, um baita empresário!

Ao mesmo tempo em que a empresária lograva introduzir novos espaços de desejo entre os filhos - que poderiam ter repercussões importantes diante da postura dos que insistiam em "ser camelôs" - também garantia a constituição de uma espécie de "carta na manga” no processo de negociação da inadimplência. Deixar de pagar e correr o risco, subjetivamente instável e desgastante, do despejo deixaria de afetar somente aos pais, já que acabaria igualmente com os novos "sonhos" de seus filhos, àquela altura já demasiadamente envolvidos com projetos de constituir carreiเo ras no mundo da moda. Assim, aceitar a tranసे. sição do camelô ao comerciante passaria a de$\stackrel{凶}{\AA}$ pender, em certa medida, de decidir entre um projeto político (a luta por um camelódromo so mais "justo" ou "sustentável”, por exemplo), de um lado, e um projeto familiar, de outro. Aos in pais cabia a difícil decisão de dar sequência is ao negócio - comprometendo suas finanças, ¿ esforços e ânimos até o limite - e, por exten๙ são, garantir a integridade de sua família, ou, $\vec{\Delta}$ então, desistir da experiência do camelódromo e, com ela, da remota possibilidade de realizar seus sonhos frustrados projetados nos filhos.

Passado o primeiro desafio, Elaine precisava, agora, intervir na maneira como os comerciantes passariam a se perceber como sujeitos dessa nova realidade em gestação:
Bom, aí nós tínhamos um nome, Camelódromo. Mas eu não podia trabalhar a segunda geração deles de novo como camelô. Então se nós vamos trazer o jovem pra dentro, pra salvar aquele passado perdido, nós temos que dar um desejo pra eles, nós temos que dar um futuro melhor, uma coisa.

Se a tal pedagogia estética do bom comerciante poderia parecer, a essa altura, demasiada utópica para convencer aos camelôs, cuja sensibilidade e humanidade, supunha-se, haviam sido destroçadas pelos anos na rua, era através da nova socialização dos filhos que se poderia atingir uma situação suficientemente equilibrada de animalidade controlada:

Isso é horrível! O que é camelódromo? Um camelô é a mesma coisa que chamar a pessoa de prostituta, de ex-presidiário, camelô: é o cara que anda com o trabalho nas costas. [...] E aí veio a Plenna, e fez pra mim o logo Shopping do Porto. Aqui nós usamos as cores da bandeira do Rio Grande do Sul [...] O que eu fazia de tarde, eu buscava valores na música gaúcha. Daí depois das seis horas eu trazia assim Pedro Ernesto Denardin, com os cantores dele, tudo na Praça de Alimentação. Pra fazer show pra eles. Pra buscar essa imagem, buscar aquilo que eles tinham perdido total. E a música gaúcha puxa muito isso: as cores do Rio Grande, a valentia do gaúcho [...] (Elaine)

Onde melhor buscar inspiração para a elaboração da nova estética do "ser comerciante” do que na música gaúcha - esse misto entre o orgulho de uma identidade local e a submissão à identidade nacional que a engloba (Oliven, 1989; 1992)? Diríamos, entre o espírito reminiscente de camelô e o de comerciante, uma condição tida como inevitável em longo prazo? Se a "selvageria" implícita ao "ser camelô" não poderia ser completamente domada, restava canalizá-la para aquilo que representava algo como um "estágio evolutivo superior" nessa escalada dos comportamentos sociais: da barbárie das ruas para a rusticidade controlada da figura subversiva e contra-hegemônica do gaúcho. Ao mesmo tempo, a música lhes permitia canalizar, simbolicamente, as agruras vivenciadas no cotidiano, como consequência da transição para o espaço ritual e confinado 
da letra e, particularmente, dos momentos dos shows. Por outro lado, essa "sociabilidade" da Praça de Alimentação - à semelhança do uso que dela é feito em Shoppings Comerciais, como veremos adiante - passou a ser o receptáculo em que os dilemas cotidianos do "doutrinamento" tomavam forma.

Eu fazia um show assim que eu gastava, sei lá quantos mil, e vinha 20 ou 30 pessoas. Os outros não queriam ir. Bom, aí um dia, um deles [...] Bom, eu fui cuspida na cara por um camelô! De tanto que ele gritou comigo! Eu ia no olho do furacão! Quando eles tavam gritando eu pegava eles pelos braços e dizia 'cala a boca, o teu grito espanta! Vocês têm que entender...'. Então eu ficava que nem um jesuíta lá no meio. Aí o cara gritou, gritou, gritou, 'porque vocês são o poder, porque o poder é esmagador, não sei o que' [...] E eu escutei, escutei, eu tava toda lavada de cuspe. E daí eu disse pra ele, 'não acredito em nada do que tu disse. Eu acredito que nós vamos vencer. E se você não acreditar, espere para ver'. (Elaine)

Certo dia, Elaine o chamou para acompanhá-la a um show de música nativista:

- E aí o show acontecendo, e ele ali no meu ouvido, 'que isso aqui não adianta fazer isso ou aquilo, que a senhora tem que fazer não sei o que e não sei o que...'. Aí eu olhei pra ele, disse 'sabe por que tu não vende? Porque tu é mal educado! Eu te convidei pra vir assistir um show, não pra vir me ensinar a administrar. E virei de costas pra ele, deixei o meu gerente da época louco, ele quase morreu. Porque eles tinham fama de que eram bandidos... Eu disse: 'te convidei pra refrigerar a tua alma. Você tem que buscar o ser humano dentro de ti. Você não pode vir como uma pedra'.

- Esse sujeito não mudou depois? Ou é o fim da história? - perguntei.

- Mudoooou! Mudou! Vai lá, ver, depois que ele perdeu uma loja, que ele viu que não tinha outra saída, quando ele viu que o vizinho dele tava próspero, aí veio, me pediu desculpas, que nunca mais iria [...] Mas tentou até o último dia, ainda, então esse daí é um da corrente ainda, que nós temos no máximo 10 pessoas que sobraram daquelas, que tipo assim oh, tão domesticados, mas não chega perto porque ele morde [risos]. (Elaine)

As conquistas de Elaine passaram rapidamente a ser catalogadas por uma poderosa assessoria de marketing e imprensa e deram origem a edições semestrais da "Revista Shopping do Porto". Além das páginas centrais - dedicadas por inteiro às fotos dos "novos modelos" vestindo roupas comercializadas pelos próprios vendedores - há espaços para os projetos de revitalização da prefeitura (com dizeres ou frases de efeito do próprio secretário, ressaltando a "modernidade" do projeto) e textos de consultores de moda, abordando as diversas tendências sobre como "vestir-se com estilo" durante a estação, ou o que consumir de maneira saudável e elegante. Da mesma forma, as histórias de ressocialização dos camelôs, inspiradas pelos trabalhos de percepção e imagem desenvolvidos com os filhos, seriam contadas posteriormente nos "cases", pequenos excertos textuais, entrecortados por fotografias e citações, destinados a criar personagens emblemáticos e persuasivos, graças ao emprego da gramática técnica do marketing e do empreendedorismo, contadas na voz subjetiva e pessoal da narradora.

\section{O ESTADO TORNADO COTIDIANO: as práticas de fiscalização}

É preciso deixar claro que, nem mesmo para o Estado, a transição ao camelódromo implicou uma passagem inequívoca para a modernidade, a legalidade e a visibilidade jurídico-formais. Se os fiscais, que agora controlam a abertura das bancas e a qualidade das mercadorias vendidas, são os mesmos que atuavam nas ruas, daí decorre que, também eles, foram alvo indireto da transição, o que lhes permite colocar em prática um leque bastante amplo de ações, que vão desde a indiferença diante de irregularidades, até práticas de abuso de poder no tratamento com os novos comerciantes.

Não é preciso dizer que este último era, no mais das vezes, o caso. Mas, também, devese lembrar que a circulação desses agentes por esses espaços gerava sentimentos e narrativas difusas, que têm a ver com o contexto geral de 
despossessão, prefigurado pela transição, e que convertia a figura ambígua do fiscal em objeto concreto de críticas que sugeriam a minoração do Estado enquanto agente legítimo a definir regras e prazos. Em tais casos, ficava evidente que os comerciantes, se ainda não estavam preparados para lidar com as dificuldades de venda e o alto valor dos aluguéis, estavam suficientemente bem instrumentados para fazer uso do "papel" - o contrato de aluguel - para legitimar seus novos direitos decorrentes do endereço comercial fixo.

A figura que mais bem encarnava as ambiguidades experimentadas pelos agentes de fiscalização no relacionamento cotidiano com os camelôs era, sem dúvidas, Mário Rodrigues $^{2}$. Desde os anos da rua, sua atuação é acompanhada das histórias contadas a seu respeito, seja da parte de detratores, seja por aqueles que, devido a seus inúmeros e difusos favores, não economizavam nos elogios. Os diários de campo estão cheios dessas citações, e basta que recuperemos apenas alguns casos, que darão a dimensão da agência de Mário e, mais importante, da distribuição de atribuições e assimetrias de poder - entre Estado e Mercado - que subjazem às tentativas de organização do tempo e do espaço.

Um deles diz respeito ao sorteio de oito ص bancas do bloco A, realizado no primeiro seจ mestre de 2011, e que permitiu que os comerФं ciantes adimplentes do bloco B, insatisfeitos com a localização de sua banca, pudessem se s candidatar a uma das poucas vagas. Alguns de

\& cremento no fluxo de vendas e da expectativa $\stackrel{\infty}{N}$ de lidar com um novo ambiente de trabalho; $\vec{i}$ outros observavam com desconfiança o processo, aparentemente transparente, pelo qual a SMIC concedia privilégios aos que já aguardavam com ansiedade, desde a chegada ao ca-

${ }^{2}$ Por questões éticas que ficarão evidentes, optei por não preservar o verdadeiro nome do agente de Estado encarregado da fiscalização. Para tanto, substituí-o pelo nome fictício de Mário Rodrigues. melódromo, pelo seu deslocamento - embora as más línguas dissessem que, na origem, problemas de inadimplência impediam a sua candidatura a uma das vagas.

Em ambos os casos, porém, era a figura de Mário que estava em evidência nas conversas de bastidor. Se, para o primeiro grupo, o fiscal era apontado como o grande responsável pelo sorteio "justo" e "transparente" dos pontos, para os detratores era justamente essa "necessidade" de visibilizar, a todo o custo, o processo de escrutínio, que tornava problemática a concessão de fato. Em outras palavras, o sorteio parecia ocultar o problema mais fundamental de que, aqui e ali, pontos eram negociados diretamente com o representante de governo, de maneira ilícita e informal - o que exigia que, de tempos em tempos, se fizesse uma demonstração ou encenação públicas do contrário.

Era sobre isso que dona Vera falava, numa certa tarde, ao citar "histórias de corredor", que circulavam anonimamente entre os comerciantes, e que davam conta de que, efetivamente, havia mais bancas em jogo, algumas das quais já tendo sido "vendidas" previamente nos espaços mais prestigiosos - exatamente como o era no "tempo da rua", argumentava. Dona Diva, outra de minhas informantes, dá conta de que outra banca já havia sido "entregue" no calor das negociações de bastidor e, não menos importante, tratava-se do mesmo agenciador que já fizera ofertas generosas de sublocação a Seu Zé e Maria de Lourdes - colegas do mesmo corredor -, e que mantinha pontos em vários setores do camelódromo.

Passado algum tempo desde o sorteio, correu a notícia de que Mário havia sido exonerado de seu posto - ou, mais especificamente, transferido internamente para outra área para ocupar uma posição menos prestigiosa. O motivo, eram unânimes ao suspeitar, não poderia ser outro que a prática de alguma irregularidade grave ou, o que dava no mesmo, a explicitação dos acordos até então mantidos na penumbra. Dona Vera parecia particularmente empertigada com as implicações de sua ausên- 
cia para a estrutura econômica local, que gravitava em torno de seu papel como agenciador e concessor de favores, pontos e produtos. Suas desconfianças emergiam da constatação de que o proprietário da banca ao seu lado havia repentinamente deixado de receber mercadorias - fato que se teria repetido em vários outros lugares -, o que seria um sinal inconteste de que, longe de proprietários, estes eram, apenas, "laranjas” de Mário, que as estariam alimentando com mercadorias apreendidas, incorporadas ilegalmente ao arsenal mercadológico do fiscal. A constatação de que esse circuito fora recentemente interrompido depunha, assim, junto com a transferência de Mário, a favor de um argumento sobre a máfia dos fiscais.

Outro episódio refere-se aos conflitos decorrentes das políticas de ocupação do espaço, e tem a ver com uma regulamentação, estabelecida pelos agentes administrativos da empresa Verdicon, sobre a delimitação de uso da parte externa das bancas - diante das práticas cada vez mais frequentes de apropriação dos corredores para a exposição de produtos. Giza, uma de minhas informantes, situada no corredor lateral esquerdo do bloco A, foi particularmente atingida pela resolução, já que mantinha mercadorias - em sua maioria chinelos de dedo, bonés e artigos esportivos - expostas na parte externa da banca, usualmente apoiadas contra a parede que ficava do outro lado do corredor e que fazia fronteira com a rua. Ainda assim, resolveu insistir na prática, até que Isabela, estilista contratada pela administração para organizar os desfiles de moda e as revistas com os filhos dos camelôs, apareceu no local, acompanhada de Mário, com o objetivo de confiscar todas as mercadorias que estivessem "na rua".

É justamente com o fiscal que Giza consegue negociar a permanência de certas estantes de produtos na parte de fora da banca, de modo que não perturbasse o fluxo de pessoas nem prejudicasse as vendas da comerciante. Isabela foi compelida, então, a concordar com o procedimento. Rumores ulteriores, contudo, dão conta de que, após o fatídico episódio, ela teria sido demitida em função dos escândalos e da intransigência quase doentia com que lidava com quem percebia e chamava de "funcionários”. Giza, por sua vez, confessou-me, enquanto caminhávamos pelos corredores, que, após o evento, os fiscais deixaram de perturbá-la, seja quanto à inspeção do espaço, seja quando estão à procura de mercadorias pirateadas: "Ficaram com medo, mas tem que ser assim, tem que saber se impor, porque senão eles tomam conta da banca! A gente ta pagando tudo direitinho!".

Edson, comerciante em permanente situação de inadimplência, nos fundos do bloco $\mathrm{B}$, não teve a mesma sorte. Com a banca situada em frente a uma antiga estrutura abandonada, na saída da Praça de Alimentação, em formato de balcão, ele cedo percebeu que poderia usar parte daquela arquitetura para expor seus produtos, basicamente bijuterias, artigos religiosos e incenso. A estratégia fora, inclusive, validada em conversa informal com Elaine, que o incentivara a fazer uso daquele espaço para ampliar sua área útil e, com isso, esperava-se, também, de sua clientela. Em pouco tempo, contudo, Mário procederia ao confisco daquelas mercadorias, tidas como fora dos padrões admissíveis de administração e distribuição do espaço.

Ambos os casos, o de Giza e de Edson, são paradigmáticos para a compreensão do que viria a se afigurar, doravante, como prática corrente de negociação dos espaços e dos produtos, nos corredores do camelódromo. De um lado, o papel ambivalente de Mário sinalizava à empresa que a prefeitura não estava interessada em comprar desentendimentos com comerciantes que, sabia-se, eram bons pagadores e faziam circular, pelos clientes que traziam, a máquina econômica local, incluindo-se nesse caso a própria praça de alimentação - à revelia do caráter de suas mercadorias (roupas esportivas de clubes de futebol) que, se não eram contrabandeadas, ainda assim eram falsificadas. Ao mesmo tempo, não havia por que ter 
complacência com sujeitos como Edson que, apesar de não alimentarem o circuito da pirataria, vendiam produtos de pouco interesse aos projetos de marketing da administração, e, ainda por cima, enfrentavam dificuldades crônicas relacionadas ao pagamento de suas despesas de manutenção.

Em pouco tempo, com o despejo de Edson em novembro de 2010, junto com mais algumas dezenas de comerciantes do bloco $\mathrm{B}$, ficaria claro que a profissionalização da figura do camelô implicava um fino ajuste no equilíbrio de forças entre agentes de fiscalização e administração sobre questões cruciais, tais como a distribuição e uso do espaço, bem como sobre o controle da qualidade e natureza dos bens colocados em circulação. Nesse processo, a importância de cada comerciante - calculada em termos da assiduidade de seus pagamentos, da quantidade de bancas acopladas, compradas ou sublocadas, sua posição estratégica na arquitetura geopolítica do espaço e a natureza da mercadoria vendida - passaria a informar o grau de tolerância da administração para com a ocupação do espaço que extrapolava os limites físicos da banca. Assim, era provável que Giza tivesse relativamente maior margem de negociação que Edson.

Nesse processo, a linguagem do shoص pping é, com efeito, o articulador, por exceণ lência, que autoriza passar da retórica da forФึ malização à desresponsabilização, por procuração, de seu papel no processo - conferido, doravante, às habilidades dos comerciantes administração. Logo, se há desentendimentos, estes devem ser procurados entre os próprios camelôs - como resultado do próprio processo de acomodação das novas experiências ou, como sugere o secretário, antes pelos resquícios ou sobrevivências do passado que ainda insiste em transubstanciar-se nas formas de sociabilidade do cotidiano. Nas palavras de Idenir Cecchim, então secretário da SMIC:

A adaptação, como todas as adaptações que se tem
nos outros grandes shoppings ou conjuntos de lojas
e centros comerciais, alguns têm mais sucesso, ou-
tros menos. Mas eu considero esse daqui, das 800
lojas, 40 ou 50 só que não deu certo, que tiveram
problema com a inadimplência, isso é o maior su-
cesso de todos. Porque as pessoas teoricamente mais
humildes são melhores pagadores. Eles pagam e fi-
cam preocupados quando não pagam. [...] Tem mais
briga pessoal lá dentro, de comadre, de cunhado,
de sócio, do que... Há muito problema de relações
humanas. Que mistura com a relação comercial [tre-
cho de entrevista realizada em 04.08.2011].

Assim, a fiscalização, em associação às políticas de socialização dos camelôs perpetradas pela empresa, opera como um importante dispositivo de favorecimento ou exclusão, seja de determinadas modalidades de bens em comercialização - tidos como menos nocivos ao mercado de falsificações, ou que colocam em movimento um fluxo mais amplo de capital ou de determinados sujeitos camelôs, alguns dos quais tidos como mais humanos que outros. Aqui os critérios são tão amplos quanto as estratégias implícitas de favorecimento, embora sugiram, num primeiro momento, uma associação entre lugar e sujeito; entre, respectivamente, o bloco B e os camelôs mais destituídos dos capitais simbólicos e econômicos necessários à sobrevivência como comerciantes bem-sucedidos no CPC. Obviamente, o argumento da transparência dos sorteios de pontos, ou das autuações de multa, ou, ainda, dos autos de fiscalização, são tanto mais eficientes quanto consigam articular, discursivamente, ambas as instâncias, ao mostrar como certos sujeitos são nocivos em função das mercadorias que veiculam e das práticas que adotam para vendê-las. 
O que Cecchim constata em seu discurso, e que a etnografia ratifica, é o fato de que as práticas dos novos comerciantes resistem a ser classificadas quer como estritamente informais e ilícitas, quer como absolutamente formais e lícitas. Da mesma forma como compete ao Estado, como condição de sua eficácia diante de outros setores da opinião pública e da sociedade civil organizada, produzir um cenário de legalização e fiscalização suficientes, as trajetórias dos sujeitos e suas mercadorias no âmbito do camelódromo apontam para uma formalização suficiente, isto é, nas palavras de Cecchim, "a meio pau" entre o pagamento dos tributos e sua completa sonegação. Trata-se de uma configuração aberta, portanto, às contradições e imprevisibilidades da prática, em que a nota fiscal fria, ou a "meia-nota", escondemse atrás do alvará concedido pela prefeitura. Assim, se para o Estado as práticas esporádicas de fiscalização são estratégicas para a produção de uma imagem eficaz de formalização e legalização unívocas, também aos camelôs a comercialização nos espaços do camelódromo traz consigo a possibilidade de um discurso sobre a formalização - adequado, por sua vez, junto com o aperfeiçoamento das réplicas e falsificações, às políticas de incremento dos preços diante de clientes cada vez mais exigentes e desconfiados da biografia daquela mercadoria (Appadurai, 2006; Kopytoff, 2006).

\section{AS ESTRATÉGIAS DE APROPRIA- ÇÃO DO TEMPO E DO ESPAÇO}

Do ponto de vista dos sujeitos afetados, o camelódromo permitiu uma progressiva flexibilização do calendário de roteiros para a abertura de novos circuitos de obtenção de mercadorias, tais como viagens para São Paulo, Rivera (Uruguai), ou, ainda, Ciudad Del Este (Paraguai). Grupos de excursões passaram a ser organizados por agentes de viagem que passaram a operar no interior do empreendimento, oferecendo preços e garantias atrativos.
Aos sujeitos que não dispõem dessa possibilidade - seja por questões financeiras, seja por indisposições, desânimos e desilusões pessoais - resta construir parcerias para que seus colegas se disponham a trazer suas mercadorias (em troca de "cuidar" da banca nos dias da viagem) ou, então, entregar-se aos intermediários e atravessadores de produtos (em crescente expansão), representantes terceirizados da cadeia de produção das mercadorias - sujeitando-se a menores margens de lucros.

Outras possibilidades - restritas aos grupos mais íntimos de sociabilidade - incluem a consignação de mercadorias, em que os produtores (geralmente um comerciante popular mais bem constituído) aceitam confiar suas mercadorias a alguém, para que as negocie e só então lhe estorne o valor de custo do produto (que pode variar, de acordo com a proximidade do sujeito em relação à sua rede de alianças). Podem incluir, alternativamente, a realização de circuitos de feiras em eventos externos ao camelódromo, a fim de compensar as parcas margens de lucro atingidas durante os processos de transição, ao mesmo tempo em que permitem, numa espécie de saudosismo nostálgico, atualizar a distância que os separa doravante da rua, retomando, mesmo que por poucos dias, a experiência do saber-fazer pedestre, desde a montagem da barraca até a vendagem ao ar livre. Por fim, resta a possibilidade, sempre presente, de desistir de todo o projeto (passando a banca "adiante" ou sublocando-a para algum conhecido que pague bem pela possibilidade de utilizar o seu espaço), face às dificuldades adaptativas, diante do desespero e do desânimo que geram inanição; enfim, diante da impossibilidade de fazer face aos sentimentos de incompletude existencial que se acumulam ao longo das semanas e meses passados na nova banca.

As imagens do que significa estar no camelódromo, para esses sujeitos, passam, igualmente, pela formação de diferentes circuitos de flexibilização e compartilhamento do "tempo" enquanto categoria social: não só é 
prestigioso cuidar ou "olhar" esporadicamente a banca do colega desavisado ou impossibilitado (que eventualmente tenha "perdido" o prazo para o pagamento ou para a abertura, no horário demarcado pelo regimento interno do camelódromo, do seu estabelecimento), senão que tal prática se estende para a formação de verdadeiros ciclos de revezamento dos dias de trabalho (de modo que uma única pessoa possa se responsabilizar por abrir e atender a loja de outros dois ou três colegas) e de circuitos de trocas simbólicas, jocosas e, fundamentalmente, de proteção mútua (pelo qual é esperado que cada sujeito seja capaz de defender, com argumentos ou desculpas, a banca de seu vizinho, sobretudo em momentos estratégicos ao jogo da fiscalização ou da empresa). É essa experiência coletiva de ser e estar no camelódromo que orienta a organização das microfinanças, das lógicas de reciprocidade local, a partir de onde são formuladas táticas de empréstimo, de concessão e de retenção de dinheiro, e são narrados e organizados, simbolicamente, os lucros e os endividamentos enquanto processos sociais.

Como destaca Seu Zé, um de meus informantes:

Daqui a um tempo, ninguém sabe o que vai acontecer com a pessoa aqui dentro. Eu posso estar bem hoje, e tu pode estar mal. Então eu vou pagar a minha parte, mas mesmo assim vou continuar no movimento pra te ajudar, e ajudar todos os que estão precisando hoje, porque pode acontecer de amanhã eu também precisar do teu apoio, quando o meu dinheiro acabar ou quando a minha situação piorar.

Vendedor de bijuterias e acessórios, a pequena banca de Seu Zé foi montada com A vários materiais e sobras de peças e exibia, de 今 início, um arsenal de cores e formas. Em frente à entrada do box, a uma distância milimétrica, encontrava-se uma gigantesca viga de concreto que impedia o acesso parcial ao interior da loja e prejudicava, portanto, as vendas. Ao realizar o deslocamento até o camelódromo, de início contrariadamente, Seu Zé engajou-se na mobilização política pela busca de melhores condi- ções de comércio, mantendo-se cético diante da nova realidade que o cercava de todos os lados.

A postura inicialmente passiva diante do turbilhão de processos sociais reverteu-se, paulatinamente, em estratégias de reinvenção da própria identidade de camelô. Uma de suas primeiras realizações consistiu em dotar a viga de concreto de novo significado, atribuindolhe, às vezes, de vitrine improvisada de seus produtos, em geral painéis de brincos e bijuterias, de modo a chamar o cliente ao longe, atraindo seu olhar na direção da mercadoria. O que parecia uma estratégia localizada transfigurou-se, num segundo momento, numa ressemantização da própria distribuição espacial de seus produtos, dos artefatos que constituíam os alicerces de sua apresentação e, finalmente, na incorporação de novas mercadorias - sobretudo de calças esportivas fabricadas por terceiros e comercializadas através de consignação.

A estratégia funcionou até o momento em que ele conseguiu trocar de banca, para o outro lado do bloco B, e ficar mais próximo de seus antigos colegas de rua. De posse do novo espaço, Seu Zé imediatamente "abriu” ambos os lados da banca, de modo a transformá-la numa pequena passagem perpendicular ao corredor principal, para que pudesse usar a parte dos fundos como uma espécie de depósito e saída para o corredor lateral, onde tinham lugar as fofocas com seus colegas de trabalho.

A falta de vendas e os altos preços cobrados pelo aluguel, contudo, continuavam a lhe incomodar. Com o tempo, e com a desarticulação progressiva da efervescência política, Seu Zé foi incorporando outras mercadorias, em sua maioria roupas de verão e de marca, trazidas pela sua colega de corredor, dona Diva, que frequentemente perfazia o circuito Argentina, Uruguai e Paraguai - e que também cuidava do ponto quando ele estava ausente. A mudança foi acompanhada por vários outros camelôs do mesmo corredor, numa espécie de onda que rapidamente se alastrou, de modo que, em pouco tempo, novamente, muitos 
camelôs passaram a vender pouco do mesmo tipo de produto.

No início de 2011, contudo, Seu Zé decidiu aposentar de vez as poucas bijuterias que ainda ficavam nos fundos da banca. Disse que não fazia sentido em função da baixa margem de lucro e da alta quantidade de vendas necessárias para o pagamento dos alugueis - as poucas que ainda sobravam seriam reaproveitadas pela filha e pela esposa, alegava. Além disso, bijuterias exigiam um maior reposicionamento e substituição constantes, colocando as mais antigas em promoção e as mais novas em posição privilegiada, devido ao ciclo de vida útil do próprio material, sujeito a desgaste. Não menos importante, o vendedor de bijuterias passou a ser cada vez mais associado como uma sobrevivência direta da rua - o que, do ponto de vista do cliente, dava maior margem à prática da barganha, ao "leve 3 e pague 2", enfim, à diminuição da taxa de lucro - material e subjetiva. Assim, após o reordenamento e reposicionamento pessoal, Seu Zé fez uma nova parceria com dona Diva, que passou a trazer casacos específicos, de vários tamanhos e modelos, do Paraguai.

Muito menos colorida, sua banca estava agora com mais mercadorias e com algum grau de exclusividade. Apesar de um tímido aumento nas vendas, Seu Zé não considera a possibilidade de ampliar o negócio ou buscar, ele mesmo, as mercadorias. Quando conversamos a respeito, disse que ainda não possuía estrutura financeira suficiente e que o importante, assim como na rua, era ter o suficiente para viver. As preocupações com o futuro e, particularmente, com o pagamento regular do aluguel, continuam todos os dias. Para ele, o camelódromo ainda não deu certo, pois suas vendas ainda não se estabilizaram para lhe dar a tranquilidade necessária sem precisar preocupar-se com o dia de amanhã. Volta e meia, o carrinho com a bagagem da banca de rua, estacionado ao lado do box no camelódromo, volta à ação, sobretudo nos finais de semana, para trabalhar nas feiras e festas populares pelo in- terior do estado e, paralelamente, alimentar as saudades dos tempos em que era dono do próprio negócio e do espaço que este ocupava. E, falando no amanhã, este se resume à chegada da Copa do Mundo a Porto Alegre: é ela que lhe dará a grande medida de se ele deverá ou não continuar tentando ser camelô num espaço planejado para engolfá-lo.

\section{CONSIDERAÇÕES FINAIS}

Vemos, assim, que a consolidação do camelódromo, primeiramente anunciado enquanto um projeto de Estado, transfigura-se para a lógica ordinária da sociabilidade cotidiana e assume novas formas concretas. Se a "lógica de mercado" passa a ser, com a implantação do empreendimento, mais que uma realidade concreta, também a racionalidade formal que orienta a formulação dessas políticas públicas, sua efetivação, coloca em jogo distintos códigos de subjetivação, de como adequar-se diferentemente aos jogos do camelô e do comerciante popular. Acima de tudo, mais que definições esquemáticas de como experimentar a transição, o projeto do camelódromo colocou em evidência uma ética tal que a própria subjetividade econômica só existe se buscada e destrinchada numa relação do sujeito consigo mesmo. Desde o discurso estético de Elaine - em que é preciso buscar o "humano" que os "anos de pedra" ter-lhes-iam subtraído -, passando pela "profissionalização" do camelô - que implica uma postura economicamente responsável diante do comércio - até os agentes de fiscalização do Estado - que lidam com "sujeitos de direitos" ou cidadãos-comerciantes, cujos atos poderão ter consequências jurídicas - "os camelôs" emergem como nova categoria de definição da realidade, para marcar o conjunto de políticas e tecnologias direcionadas para esse setor da população que só existe quando sua própria subjetividade é reconfigurada nos marcos do mercado, da inclusão social e das políticas empreendedoras 
(Foucault, 1979; 1984).

Nesse processo, talvez os próprios camelôs, mais do que quaisquer outros sujeitos, compreendam o significado da irreversibilidade do processo a que foram - alguns compulsoriamente - submetidos. Mais que adequações "morais", foram também eles que demonstraram que suas trajetórias e noções do que seja o (in)formal, o (i)lícito, a (in)civilidade, a política, a economia e tantas outras coisas mais, não se opõem à emergência de projetos com foco no homo economicus previsto pelo "comerciante popular" ou pelo "microempresário". Antes, pelo contrário: os novos espaços e tempos de sociabilidade do camelódromo permitiram reconfigurar tais saberes ao apontarem para os limites do escopo formalizador e "inclusivo" do cidadão-comerciante enquanto um "projeto", isto é, um constante "vir a ser" que, para efetivar-se, não pode prescindir da trajetória dos próprios camelôs. Os mesmos corredores, espaços, paredes, balcões, produtos, máquinas de cartão de crédito, que, supostamente, aplainariam relações e homogeneizariam saberes, provaram-se a base material para um reordenamento da própria expertise comercial, do significado de se estar na história e, mais amplamente, da verdade sobre si; são, em uma palavra, a metáfora que jamais deixará ㅇํ vos "comerciantes populares".

Recebido para publicação em 25 de julho de 2014 Aceito em 27 de outubro de 2014

\section{REFERÊNCIAS}

AGUIAR, Julia Saldanha Vieira de. Camelódromo da Praça $X V$ : improviso, comunicação e auto-organização. 2007. Monografia (Conclusão de Curso) - Departamento de Comunicação da Universidade Federal do Rio Grande do Sul.

APPADURAI, Arjun. Introduction: commodities and the politics of value. In: . (org.) The social life of things. Cambridge: Cambridge Un. Press, 2006. p. 3-63.

CUNHA, Manuela I. P. da. Formalidade e informalidade: questões e perspectivas. Etnográfica, Vol. X (2), p. 219231,2006
FOUCAULT, Michel. A Governamentalidade. In: Microfísica do Poder. Rio de Janeiro: Graal, 1979. p. 277293

FOUCAULT, Michel. Introdução: a problematização moral dos prazeres. In: . História da Sexualidade 2: o uso dos prazeres. Rio de Janeiro: Graal, 1984. p. 7-32.

KOPPER, Moisés. De camelôs a lojistas: etnografia da transição do mercado de rua para um shopping popular em Porto Alegre-RS. 2012. Dissertação (Mestrado em Antropologia) - Programa de Pós-Graduação em Antropologia Social da Universidade Federal do Rio Grande do Sul.

KOPYTOFF, Igor. The cultural biography of things: commoditization as process. In: APPADURAI, Arjun (org.). The social life of things. Cambridge: Cambridge University Press, 2006. p. 64-94.

LEITE, Rogerio Proença. Contra-Usos e Espaço Público: notas sobre a construção social dos lugares na Manguetown. Revista Brasileira de Ciências Sociais, São Paulo, Vol. 17, n. ${ }^{\circ}$ 49, p. 115-134, 2002.

Espaço público e política dos lugares: usos do patrimônio cultural na reinvenção contemporânea do Recife Antigo. 2001. Tese (Doutorado em Antropologia Social) - Instituto de Filosofia e Ciências Humanas da Unicamp.

MACHADO DA SILVA, Luís Antonio. Da informalidade à empregabilidade. Caderno CRH, Salvador, n. 37, p. 81109, 2002.

MAFRA, Patrícia Delgado. A "pista" e o "camelódromo": camelôs no Centro do Rio de Janeiro. 2005. Dissertação (Mestrado em Ciências Sociais) - Programa de PósGraduação em Sociologia e Antropologia da Universidade Federal do Rio de Janeiro.

NORONHA, Eduardo G. 'Informal', Ilegal, Injusto: percepções do mercado de trabalho no Brasil. Revista Brasileira de Ciências Sociais, São Paulo, v. 18, n. 53, p. 111-129, 2003.

OLIVEN, Ruben G. O Rio Grande do Sul e o Brasil: uma relação controvertida. Revista Brasileira de Ciências Sociais, São Paulo, v. 3, p. 5-14, 1989.

. A parte e o todo: a diversidade cultural no BrasilNação. Petrópolis: Vozes, 1992.

PINHEIRO-MACHADO, Rosana. 'A garantia soy yo': etnografia das práticas comerciais entre camelôs e sacoleiros na cidade de Porto Alegre e na fronteira Brasil/ Paraguai. 2004. Dissertacão (Mestrado em Antropologia Social) - Programa de Pós-Graduação em Antropologia Social da Universidade Federal do Rio Grande do Sul.

Made in China: produção e circulação de mercadorias no circuito China-Paraguai-Brasil. 2009. Tese (Doutorado em Antropologia Social) - Programa de Pós-Graduação em Antropologia Social da Universidade Federal do Rio Grande do Sul.

RABOSSI, Fernando. Nas ruas de Ciudad del Este. 2004. Tese (Doutorado em Antropologia Social) - Programa de Pós-Graduação em Antropologia Social do Museu Nacional/Universidade Federal do Rio de Janeiro.

RIBEIRO, Gustavo Lins. A globalização popular e o sistema mundial não-hegemônico. Revista Brasileira de Ciências Sociais, São Paulo, v. 25, n. 74, p. 21-38, 2010.

Economic globalization from below. Etnográfica, v. 10, n. 2, p. 233-249, 2006. 


\section{FROM STREET VENDORS TO SHOP OWNERS: the transition from street markets to a mall in Porto Alegre}

Moisés Kopper

This article starts off from the tensions involved in the process of removing the street Market from downtown Porto Alegre/RS, Brazil, and moving it to a popular mal built through a Public-Private Partnership (PPP). We gave preference to an ethnographic approach based on over three years of insertion if the field, which allowed us to capture the process from a diachronic perspective. The transition from the streets to the mall was closely followed by the construction company, that demanded a change in commercial sensibility from a pedagogical perspective with the aim of creating new profiles for the shopkeepers, something that was essential for the economic success of the investment. As a consequence, new conflicts emerged daily from this strategy, since not all street vendors became the prototype of shopkeeper idealized by the PPP. The tensions around this process allowed us to reconstruct the connections between economy and politics, micro and macro, agents and institutions that shape the social.

KeYwords: Informal Market. Street vendors. State. Ethnography. Public-Private Partnership.

\section{DE CAMELOTS À COMMERÇANTS: la transition d'un marché à ciel ouvert à un centre commercial à Porto Alegre}

Moisés Kopper

Les tensions dues au processus d'élimination du marché à ciel ouvert dans le centre de Porto Alegre/ RS et de son transfert vers un centre commercial populaire, construit grâce à un partenariat publicprivé (PPP), sont à l'origine de cet article. On y privilégie une approche ethnographique faite à partir d'une insertion sur le terrain pendant plus de trois ans, ce qui a permis d'en saisir le processus dans une perspective diachronique. La transition de la rue vers le "camelotdrome" a été suivie de près par l'entreprise de construction dorénavant responsable de sa gestion. Ceci exigeait un changement de sensibilité commerciale grâce à une politique de "pédagogisation" pour créer un nouveau profil de commerçants, condition indispensable à la réussite économique de cette réalisation. L'une des conséquences est que de nouveaux types de conflits surgissent tous les jours de cette stratégie, car tous les camelots ne se sont pas reconvertis selon le prototype du commerçant conçu par le PPP. Les tensions autour de ce processus permettent de reconstituer les liens existants entre l'économie et la politique, micro et macro, les agents et les institutions qui forment le social.

Mots-CLÉs: Marché Informel. Camelots. État. Ethnograhie. Partenariat Public-Privé.

Moisés Kopper - Doutorando em Antropologia Social pelo Programa de Pós-Graduação da Universidade Federal do Rio Grande do Sul. Atua nos seguintes temas: Antropologia Urbana, da Política, do Estado, da Economia; democracia participativa, culturas populares, mercados informais, classes médias, estratificação e mobilidade social. Principais publicações: "Etnografia de um Mercado em Transição": Teoria \& Sociedade, v. 19, p. 228-253, 2011; "Política, Economia e Mediação Simbólica”: Cadernos de Campo, v. 20, 2012; “Tempos de Transição”: NORUS, v. 1, p. 95-119, 2013. 
